\title{
Pemilihan rute jalan tol menggunakan model pilihan diskrit dari pengguna
}

\author{
Darmawan Adi Susanto $^{a}$, Aleksander Purba ${ }^{b},{ }^{*}$, Chatarina Niken ${ }^{c}$ \\ a Mahasiswa Magister Teknik Sipil, Universitas Lampung, Jl. Soemantri Brojonegoro No. 1 Bandar Lampung, 35145, Indonesia \\ ${ }^{b}$ Jurusan Teknik Sipil, Universitas Lampung, Jl. Soemantri Brojonegoro No. 1 Bandar Lampung, 35145, Indonesia \\ c Jurusan Teknik Sipil, Universitas Lampung, Jl. Soemantri Brojonegoro No. 1 Bandar Lampung, 35145, Indonesia
}

\section{H I G H L I G H T S}

- Penelitian tentang model probabilitas pemilihan rute di ruas jalan tol Terbanggi Besar- Pematang Panggang .

- Tarif tol berpengaruh terhadap sensitifitas probabilitas pengguna jalan tol.

- Penghematan waktu tempuh merupakan atribut yang sangat sensitif terhadap probabilitas penggunaan jalan tol.

\section{N F O A R TIKE L}

\section{Riwayat artikel:}

Diterima 14 Mei 2020

Diterima setelah diperbaiki 10 Juni 2020

Diterima untuk diterbitkan 15 Juni 2020

Tersedia secara online 01 Agustus 2020

\section{Kata kunci:}

Rute jalan tol,

model pilihan diskrit,

logit binomial,

stated preference.

\begin{abstract}
A B S T R A K
Tujuan penelitian adalah untuk mendapatkan model pilihan rute yang dapat menjelaskan probabilitas pengguna jalan memilih jalan tol, dan untuk memperkirakan sensitivitas pilihan rute jika terjadi perubahan pada atributnya. Kuisioner stated preference digunakan sebagai media untuk mendapatkan data primer. Kuisioner ini ditujukan kepada pengguna kendaraan golongan I pada jalan tol Terbanggi Besar - Pematang Panggang. Formulir survei didesain menjadi dua bagian yang berisi data karakteristik responden dan data preferensi responden dengan empat level pilihan dari dua variabel bebas: kenaikan tarif tol dan penghematan waktu tempuh. Data yang diperoleh kemudian dianalisa dengan model logit binomial untuk mendapatkan model regresi linear selisih utilitasnya. Dalam model juga dimasukkan faktor karakteristik tingkat pendapatan responden. Berdasarkan hasil analisis menunjukkan bahwa atribut yang paling sensitif mempengaruhi model pilihan rute adalah penghematan waktu tempuh.
\end{abstract}

Diterbitkan oleh Jurusan Teknik Sipil Universitas Lampung

\section{Pendahuluan}

Jalan merupakan bagian dari infrastruktur transportasi darat yang berperan penting dalam meningkatkan pertumbuhan ekonomi nasional. Jalan tol adalah bagian dari jaringan jalan umum yang perwujudannya adalah tanggung jawab pemerintah. Jalan tol Terbanggi Besar - Pematang Panggang merupakan salah satu ruas dari jalan tol Trans Sumatera. Pembangunan jalan tol ini merupakan salah satu bagian dari proyek strategis nasional yang dilakukan untuk mendorong pengembangan kawasan di Pulau Sumatera.

Pembangunan jalan tol dibiayai sebagian atau seluruhnya oleh pengguna jalan melalui pengenaan tarif tol. Tarif tol dan jumlah pengguna adalah faktor utama bagi pengguna jalan untuk memilih rute jalan tol. Oleh karena itu, masyarakat yang memilih jalan tol akan mendapatkan nilai tambah yang diperoleh berupa penghematan biaya operasi

\footnotetext{
* Penulis koresponden.

Alamat e-mail: aleksander.purba@eng.unila.ac.id (A. Purba). Peer review dibawah tanggung-jawab Jurusan Teknik Sipil Universitas Lampung.

https://doi.org/10.23960/rekrjits.v24i2.13
}

kendaraan, waktu tempuh, kenyamanan dan fasilitas yang lebih baik.

Tujuan dari penelitian ini adalah untuk mendapatkan model pilihan rute yang dapat menjelaskan probabilitas pengguna memilih jalan tol berdasarkan atribut perjalanan, yaitu tarif, penghematan waktu tempuh dan variabel pendapatan pengguna. Selain itu, penelitian ini juga bertujuan untuk mengetahui sensitivitas pilihan rute ketika perubahan atribut perjalanan dilakukan.

\section{Metode Penelitian}

Penelitian ini merupakan studi kasus yang menggunakan metode pendekatan deskripsi analitis dan data kualitatif yang dikuantitatifkan. Lokasi penelitian di jalan tol trans Sumatera, ruas Terbanggi Besar - Pematang Panggang di Propinsi Lampung dengan panjang rute $112 \mathrm{~km}$. Saat dilakukan penelitian, ruas jalan tol ini masih dalam masa uji coba operasional dan belum diberlakulan tarif bagi penggunanya.

Tahap awal penelitian adalah survei pendahuluan. Data dari survei pendahuluan kemudian digunakan sebagai dasar untuk menentukan desain kuisioner. Kuisioner terdiri 
dari dua bagian, lembar pertama berisi data identitas dan karakteristik responden sedangkan lembar kedua berisi data preferensi responden. Kuisioner diberikan kepada 210 responden pengguna jalan tol Terbanggi Besar - Pematang Panggang dengan kualifikasi Golongan-1 mobil pribadi. Pembatasan ini dilakukan dengan asumsi pengguna kendaraan pribadi pengambil keputusan dalam pemilihan rute. Survei dilakukan di dua lokasi yaitu rest area KM 234A dan rest area KM 215B. Survei dilakukan selama dua hari pada tanggal 26 - 27 Desember 2019 pada masa liburan akhir tahun. Dari 210 kuisioner yang disebarkan kepada responden, 190 data responden dinyatakan memenuhi syarat sebagai data untuk analisis selanjutnya. Sedangkan, 20 data responden dinyatakan tidak memenuhi syarat karena jawaban tidak lengkap.

Kemudian, pernyataan preferensi responden terhadap alternatif pilihan menggunakan data rating. Data ini dinyatakan dalam skala semantik yaitu: pasti memilih jalan tol, mungkin memilih jalan tol, mungkin tidak memilih jalan tol dan pasti tidak memilih jalan tol. Kurniati dan Fasha [1], menyatakan bahwa probabilitas pada skala numerik ditentukan dengan mengurutkan data dari besar ke kecil atau sebaliknya. Penggambaran posisi (plotting position) yang dipakai adalah seperti Persamaan 1.

$$
P\left(X_{m}\right)=\frac{m}{n+1} x 100 \%
$$

dengan $P\left(X_{m}\right)$ adalah data yang dirangking dari besar ke kecil, $\mathrm{m}$ adalah nomor urut dan $n$ adalah jumlah data.

Untuk mencapai tujuan penelitian ini, maka pada tahapan selanjutnya dilakukan analisis data primer yang telah didapat. Pertama dilakukan analisis regresi menggunakan model logit binomial untuk mendapatkan model selisih utilitas antara jalan tol dan jalan non-tol. Pada analisis ini dilakukan beberapa uji statistik antara lain uji-t, $u j i-F$, uji multikolinearitas dan uji koefisien determinasi $\left(\mathrm{R}^{2}\right)$. Analisis regresi dilakukan dengan bantuan program komputer. Dari model ini kemudian dibuat grafik sensitivitas tarif tol dan grafik sensitivitas penghematan waktu terhadap probabilitas pemilihan rute jalan tol. Nilai elastisitas dihitung dengan rumus arc elasticity.

\section{Hasil dan Pembahasan}

Karakteristik responden berdasarkan usia, pekerjaan, pendapatan per bulan, tingkat pendidikan dan biaya transportasi per bulan dapat dilihat pada Tabel 1 - Tabel 5. Dari hasil rekapitulasi data menunjukkan bahwa 32,1\% responden berusia 36-45 tahun, 48,9\% responden berprofesi sebagai wiraswasta/tani, $29,5 \%$ responden dengan pada kelompok pendapatan 2-4 juta per bulan serta kelompok pendapatan $4-6$ juta per bulan, 42,1\% responden memiliki tingkat pendidikan SD/SMP/SMA, dan $57,4 \%$ responden yang memiliki biaya transportasi 500 ribu - 1 juta per bulan.

Tabel 1

Usia responden

\begin{tabular}{llll}
\hline No & Usia responden & Jumlah & $\%$ \\
\hline 1 & $17-25$ tahun & 12 & 6,3 \\
2 & $26-35$ tahun & 53 & 27,9 \\
3 & $36-45$ tahun & 61 & 32,1 \\
4 & $46-55$ tahun & 46 & 24,2 \\
5 & $>56$ tahun & 18 & 9,5 \\
Jumlah & & 190 & 100,0 \\
\hline
\end{tabular}

Tabel 2

Pekerjaan Responden

\begin{tabular}{llll}
\hline No & Pekerjaan responden & Jumlah & $\%$ \\
\hline 1 & PNS / TNI / POLRI & 50 & 26,3 \\
2 & Pelajar / Mahasiswa & 5 & 2,6 \\
3 & Karyawan Swasta / BUMN & 24 & 12,6 \\
4 & Wiraswasta / Tani & 93 & 48,9 \\
5 & Lainnya & 18 & 9,5 \\
Jumlah & & 190 & 100,0 \\
\hline
\end{tabular}

Tabel 3

Pendidikan responden

\begin{tabular}{llll}
\hline No & Pendidikan responden & Jumlah & $\%$ \\
\hline 1 & SD/SMP/SMA & 80 & 42,1 \\
2 & Diploma & 16 & 8,4 \\
3 & S1 & 79 & 41,6 \\
4 & S2 & 15 & 7,9 \\
Jumlah & & 190 & 100,0 \\
\hline
\end{tabular}

Tabel 4

Pendapatan per bulan responden

\begin{tabular}{llll}
\hline No & Pendapatan per bulan & Jumlah & $\%$ \\
\hline 1 & $<1$ juta & 5 & 2,6 \\
2 & $1-2$ juta & 20 & 10,5 \\
3 & $2-4$ juta & 56 & 29,5 \\
4 & $4-6$ juta & 56 & 29,5 \\
5 & $6-8$ juta & 25 & 13,2 \\
6 & $8-10$ juta & 12 & 6,3 \\
7 & $>10$ juta & 16 & 8,4 \\
Jumlah & & 190 & 100,0 \\
\hline
\end{tabular}

Tabel 5

Biaya Transportasi per bulan Responden

\begin{tabular}{llll}
\hline No. & $\begin{array}{l}\text { Biaya Transportasi per } \\
\text { bulan Responden }\end{array}$ & Jumlah & $\%$ \\
\hline 1 & $<500$ ribu & 50 & 26,3 \\
2 & 500 ribu -1 juta & 109 & 57,4 \\
3 & $2-3$ juta & 28 & 14,7 \\
4 & $>4$ juta & 3 & 1,6 \\
Jumlah & & 190 & 100,0 \\
\hline
\end{tabular}

Selanjutnya, persamaan model logit binomial pemilihan rute jalan tol atau jalan non-tol dibuat dengan menggunakan data primer hasil survei stated preference. Persamaan tersebut merupakan fungsi selisih utilitas antara rute jalan tol dan non-tol. Fungsi selisih utilitas diperoleh dengan metode regresi linear berganda dan dimodifikasi dengan cara mentransformasi data rating menjadi skala numeris sehingga diperoleh persamaan linear transformasi. Transformasi skala numerik dapat dilihat pada Tabel 6 . Sedangkan analisis persamaan fungsi selisih utilitas dilaksanakan seperti pada Tabel 7.

Fungsi selisih utilitas antara jalan tol dan non-tol diperoleh dengan analisis regresi linear berganda sesuai dengan Persamaan 2.

$$
\begin{aligned}
Y= & a+b_{1}\left(X_{1 \text { tol }}-X_{1 \text { non.tol }}\right)+b_{2}\left(X_{2 t o l}-X_{2 n o n . t o l}\right) \\
& +\ldots .+b_{n}\left(X_{\text {ntol }}-X_{\text {nnon.tol }}\right)
\end{aligned}
$$

dengan $Y$ adalah fungsi selisih utilitas antara jalan tol dan jalan non-tol, $\left(X_{1 \text { tol }}-X_{1 \text { non.tol }}\right)$ adalah variasi kenaikan tarif tol, dan $\left(X_{2 t o l}-X_{2 n o n . t o l}\right)$ adalah variasi penghematan waktu antara jalan tol dan non-tol.

Selanjutnya, Tabel 8 memperlihatkan hasil kalibrasi model pemilihan rute. Dari kalibrasi diperoleh model selisih utilitas terbaik antara jalan tol dan non-tol dengan varibel bebas $X_{1}$ adalah variabel tarif tol, $X_{2}$ adalah variable penghematan waktu tempuh dan $X_{4}$ adalah variabel pendapatan per bulan yang ditunjukkan oleh Persamaan (3). 
Tabel 6

Transformasi skala numerik

\begin{tabular}{llll}
\hline & & \multicolumn{2}{c}{ Nilai transformasi } \\
\cline { 3 - 4 } Rating & Point & Skala probabilitas & Skala numerik \\
& Rating & $P\left(\mathrm{X}_{m}\right)=\frac{m}{n+1} \times 100 \%$ & $\operatorname{Ln}\left[\frac{P_{1}}{1-P_{1}}\right]$ \\
\hline Pasti memilih jalan tol & $\mathrm{A}$ & 0,8 & 1,386 \\
Mungkin memilih jalan tol & $\mathrm{B}$ & 0,6 & 0,405 \\
Mungkin tidak memilih jalan tol & $\mathrm{C}$ & 0,4 & $-0,405$ \\
Pasti tidak memilih jalan tol & $\mathrm{D}$ & 0,2 & $-1,386$ \\
\hline
\end{tabular}

Tabel 7

Matrik korelasi variabel bebas

\begin{tabular}{lllllll}
\hline & $Y$ & $X_{1}$ & $X_{2}$ & $X_{3}$ & $X_{4}$ & $X_{5}$ \\
\hline$Y$ & 1 & & & & & \\
$X_{1}$ & $-0,699$ & 1 & & & & \\
$X_{2}$ & 0,495 & $-0,471$ & 1 & & & \\
$X_{3}$ & 0,237 & $-0,174$ & 0,154 & 1 & & \\
$X_{4}$ & 0,851 & $-0,542$ & 0,293 & 0,292 & 1 & \\
$X_{5}$ & 0,443 & $-0,292$ & 0,143 & 0,146 & 0,514 & 1 \\
\hline
\end{tabular}

dengan $Y$ adalah fungsi dengan skala numerik, $X_{1}$ adalah variabel tarif tol, $X_{2}$ adalah variabel penghematan waktu tempuh, $X_{3}$ adalah variabel tingkat pendidikan, $X_{4}$ adalah variabel pendapatan per bulan dan $X_{5}$ adalah variabel biaya transportasi per bulan.

Tabel 8

Hasil kalibrasi model pemilihan rute

\begin{tabular}{llllll}
\hline Variabel & $\begin{array}{l}\text { Koefisien } \\
\text { regresi }\end{array}$ & t-hitung & Sign.t & $\begin{array}{l}\text { Tole- } \\
\text { rance }\end{array}$ & VIF \\
\hline Konst. & $-1,711$ & $-10,150$ & 0,000 & & \\
$X_{1}\left(\mathrm{~b}_{1}\right)$ & -0.000009208 & $-6,568$ & 0,000 & 0,600 & 1,667 \\
$X_{2}\left(\mathrm{~b}_{2}\right)$ & 0,186 & 5,270 & 0,000 & 0,776 & 1,288 \\
$X_{4}\left(\mathrm{~b}_{4}\right)$ & 0,446 & 18,265 & 0,000 & 0,705 & 1,419 \\
$\mathrm{~F}_{\text {hitung }}$ & \multicolumn{3}{c}{301,672} \\
Sign.F & 0,000 & & \\
$\mathrm{R}^{2}$ & \multicolumn{3}{c}{0,830} & & \\
\hline
\end{tabular}

$$
Y=-1,711-0,000009208 X 1+0,186 X 2+0,446 X 4
$$

Dari hasil $u j i-t$ diperoleh nilai $t_{\text {hitung }}$ pada konstanta adalah -10,150, $X_{1}$ adalah -6,568, $X_{2}$ adalah 5,270 dan $X_{4}$ adalah 18,265 dan signifikansi semua variabel adalah 0,000 . Dengan $t_{\text {tabel }}$ sebesar 1,973 , nilai $-t_{\text {hitung }}<-t_{\text {tabel }}$ atau $t_{\text {hitung }}>t_{\text {tabel }}$ dan signifikansi $>0,005$ maka semua variabel diatas signifikan. Secara parsial masing - masing variabel bebas di atas dapat digunakan pada model. Selanjutnya, dari hasil Uji-F diperoleh nilai $F_{\text {hitung }}$ sebesar 301,672 dengan signifikansi 0,000 . Dengan $F_{\text {tabel }}$ adalah2,653, nilai $F_{\text {hitung }}>F_{\text {tabel }}$ dan signifikansi $<0,005$ maka secara bersamasama variabel tersebut signifikan dan dapat digunakan pada model.

Dari perhitungan dengan menggunakan program statistik, diperoleh nilai koefisien determinasi $\left(R^{2}\right)$ sebesar 0,83 . Hal ini menunjukkan kontribusi variabel-variabel bebas terhadap variabel tidak bebas sebesar $83 \%$. Sisanya $17 \%$ dipengaruhi oleh faktor lain. Uji multikolinearitas dari perhitungan dengan menggunakan program statistik, pada variabel $X_{1}$ (tarif tol), $X_{2}$ (penghematan waktu tempuh) dan $X_{4}$ (pendapatan) diperoleh nilai VIF sebesar 1,667; 1,288; dan 1,419 serta nilai tolerance sebesar 0,$600 ; 0,776$ dan 0,705 . Pada semua variabel nilai $\mathrm{VIF}<10$ dan nilai tolerance $>0,1$ sehingga dapat dinyatakan tidak terjadi multikolinearitas.
Kemudian dilaksanakan model pemilihan rute dengan persamaan "selisih utilitas" ( $\left.U_{t o l}-U_{\text {non.tol }}\right)$ ditunjukkan oleh Persamaan (4) berikut ini:

$$
Y=-1,711-0,000009208 . X_{1}+0,186 . X_{2}+0,446 . X_{4}
$$

Setelah diperoleh persamaan selisih utilitas pemilihan rute jalan tol dan non-tol maka model probabilitas pemilihan rute dapat ditulis sesuai Persamaan (5) dan (6). Persamaan probabilitas rute jalan tol adalah:

$$
P_{\text {tol }}=\left[\frac{e^{\left(-1,711-0,000009208 . X_{1}+0,186 . X_{2}+0,446 . X_{4}\right)}}{1+e^{\left(-1,711-0,000009208 . X_{1}+0,186 . X_{2}+0,446 . X_{4}\right)}}\right]
$$

Sedangkan Persamaan (6) adalah probabilitas rute jalan non-tol

$$
P_{\text {non-tol }}=1-P_{\text {tol }}
$$

dengan $Y$ adalah fungsi selisih utilitas dengan skala numerik, $X_{1}$ adalah variabel tarif tol, $X_{2}$ adalah variabel penghematan waktu tempuh dan $X_{4}$ adalah variabel pendapatan per bulan.

Sensitivitas model digambarkan dengan grafik sensitivitas dari perubahan masing - masing atribut. Dari grafik, dapat dilihat adanya perubahan probabilitas pilihan jalan tol jika dilakukan perubahan nilai atribut secara bertahap. Berdasarkan grafik sensitivitas tarif tol dapat dilihat bahwa kemiringan garis menunjukkan arah negatif, menyatakan bahwa semakin besar kenaikan tarif tol maka akan menurunkan probabilitas pengguna memilih jalan tol. Sedangkan berdasarkan grafik sensitivitas penghematan waktu tempuh, dapat dilihat bahwa kemiringan garis menunjukkan arah positif, menyatakan bahwa semakin besar penghematan waktu tempuh maka akan menaikkan probabilitas pengguna memilih jalan tol.

Nilai elastisitas ditentukan dengan perhitungan arc elasticity yang berbasis pada model probabilitas pemilihan rute. Grafik sensitivitas antara tarif tol dan penghematan waktu tempuh dengan probabilitas pemilihan rute jalan tol atau non-tol dapat dilihat pada Gambar 1 dan Gambar 2. Dari Gambar 1 diperoleh nilai kenaikan tarif preferensi $\left(\Delta P_{\text {pref }}\right)$ sebesar Rp 40.500 sehingga diperoleh tarif preferensi ( $P$ pref) sebesar Rp 141.300. Dari Gambar 2 diperoleh nilai penghematan waktu tempuh preferensi ( $\left.T_{\text {pref }}\right)$ sebesar 2 jam.

\section{Simpulan}

Berdasarkan pengolahan data hasil survei terhadap pengguna jalan tol Terbanggi Besar - Pematang Panggang, faktor yang berpengaruh terhadap pemilihan rute oleh pengguna jalan adalah tarif tol, penghematan waktu tempuh dan pendapatan per bulan. Berdasarkan grafik sensitivitas tarif tol menunjukkan arah negatif (-), semakin besar kenaikan tarif tol maka akan mengurangi probabilitas 
pengguna memilih jalan tol. Sebaliknya, berdasarkan grafik sensitivitas penghematan waktu tempuh menunjukkan arah positif (+), semakin besar penghematan waktu tempuh maka akan menaikkan probabilitas pengguna memilih jalan tol. Sedangkan berdasarkan hasil analisis elastisitas, diketahui bahwa penghematan waktu tempuh adalah atribut yang paling sensitif terhadap probabilitas pengguna dalam memilih jalan tol.

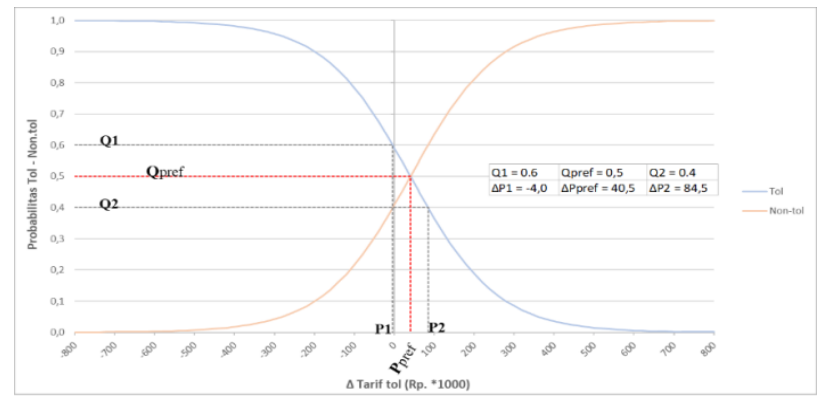

Gambar 1 Grafik sensitivitas tarif tol

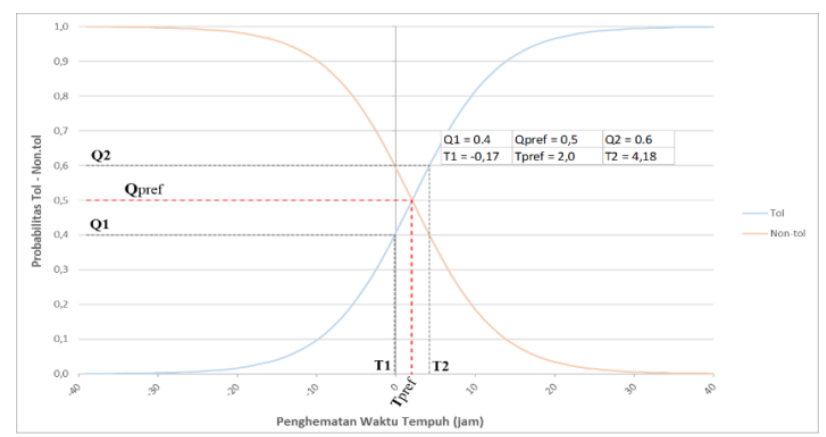

Gambar 2 Grafik sensitivitas penghematan waktu tempuh

\section{Daftar Pustaka}

[1] Kurniati, Fasha.: Pemodelan pemilihan antara mobil pribadi parkir inap dan taksi pada bandara international minangkabau (BIM) dengan teknik stated preference Jurnal Eko Rekayasa, 10, 2, 2014

[2] Hensher: Stated preference analysis of travel choices, the state practice. Institute of Transport Studies, Graduate School of Business, the University of Sidney, 1993

[3] Hermawan, R.: Kaji ulang penentuan tarif dan sistem penggolongan kendaraan jalan tol di Indonesia. Jurnal Teknik Sipil dan Terapan Bidang Teoritis, 16, 2, 2009

[4] Kockelman, K.M., Chen, T.D., Larsen, K.A., Nichols, B.G.: The economics of transportation systems: a reference for practitioners. Create Space is a DBA of On-Demand Publishing LLC. 2013

[5] Litman, T.: Understanding transport demands and elasticities, how prices and other factors affect travel behavior, Victoria Transport Policy Institute, 2018

[6] Ortuzar, Willumsen: Modelling transport. 4rd edition, John Wiley \& Sons Ltd, The Atrium, Southern Gate, Chichester, West Sussex, United Kingdom, 2011

[7] Rodrigue, J.P.: The geography of transport systems. Department of Global Studies and Geography at Hofstra University, New York, 2017

[8] Tamin, O.Z:: Perencanaan dan pemodelan transportasi, Penerbit ITB, Bandung, 2000 